\title{
Erratum to: Prediction of the mechanical behavior of flax polypropylene composites based on multi-scale finite element analysis
}

\author{
Yucheng Zhong ${ }^{1}$, Le Quan Ngoc Tran ${ }^{2}$, Umeyr Kureemun ${ }^{1}$ (D), and Heow Pueh Lee ${ }^{1, *}$ \\ ${ }^{1}$ Department of Mechanical Engineering, National University of Singapore, 9 Engineering Drive 1, Singapore 117576, Singapore \\ ${ }^{2}$ Singapore Institute of Manufacturing Technology (SIMTech), A*Star, 71 Nanyang Drive, Singapore 638075, Singapore
}

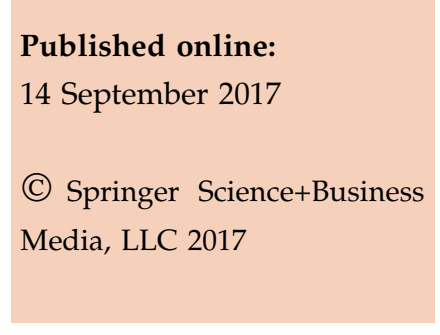

\section{Erratum to: J Mater Sci (2017) 52:4957-4967 DOI 10.1007/s10853-016-0733-7}

The article Prediction of the mechanical behavior of flax polypropylene composites based on multi-scale finite element analysis, written by Yucheng Zhong, Le Quan Ngoc Tran, Umeyr Kureemun, and Heow Pueh Lee, was originally published Online First without open access. After publication in volume 52, issue 9, pages 4957-4967 the author decided to opt for Open Choice and to make the article an open access publication. Therefore, the copyright of the article has been changed to (c) The Author(s) 2017 and the article is forthwith distributed under the terms of the Creative Commons Attribution 4.0 International License (http://creativecommons.org/licenses/by/ $4.0 /$ ), which permits use, duplication, adaptation, distribution, and reproduction in any medium or format, as long as you give appropriate credit to the original author(s) and the source, provide a link to the Creative Commons License, and indicate if changes were made.

The online version of the original article can be found under doi:10.1007/s10853-016-0733-7.

Address correspondence to E-mail: mpeleehp@nus.edu.sg 